\title{
Intraspecific variation in foraging behaviour: influence of shore height on temporal organization of activity in the chiton Acanthopleura japonica
}

\author{
Jasmine S. S. Ng*, Gray A. Williams \\ The Swire Institute of Marine Science, Department of Ecology \& Biodiversity, The University of Hong Kong, Pokfulam Road, \\ Hong Kong, SAR China
}

\begin{abstract}
The chiton Acanthopleura japonica has a wide vertical distribution on moderately exposed Hong Kong shores, and it shows limited seasonal vertical migration. Observations revealed that chitons were active while awash on ebbing or flooding tides during both day- and night-time, but they were inactive in refuges at their resting shore heights when conditions were unfavourable. The most intense activity was always associated with awash periods, but the timing of activity peaks and percentage activity varied between seasons, tidal conditions and the shore height individuals occupied. Activity periods were longer in summer than winter, but varied from day to day, depending on weather conditions such as wind speed and hours of sunshine. Duration of activity also varied with shore height; chitons living in the high-shore remaining active for nearly twice as long as those lower on the shore. Laboratory studies showed that activity was controlled by a circalunidian endogenous rhythm, but can be overridden by exogenous, environmental factors, such as wave splash. Therefore, the temporal organization of activity in A. japonica is controlled by both exogenous and endogenous mechanisms, of which the timing and duration of the awash phase of the tide appears to be the dominant controlling factor. To optimize foraging success, individuals exhibit a continuum of foraging strategies determined by season and the shore height they occupy, resulting in intraspecific variability in the duration and timing of activity.
\end{abstract}

KEY WORDS: Behavioural plasticity $\cdot$ Endogenous rhythms $\cdot$ Feeding strategies $\cdot$ Optimal foraging · Seasonal, tropical rocky shores

\section{INTRODUCTION}

Most grazing molluscs inhabit a narrow belt in the rocky intertidal and, as such, experience varying degrees of emersion and submersion as a result of tidal movement. To accommodate this, grazers have developed a variety of activity patterns (Hawkins \& Hartnoll 1983), and they often forage at a certain location on the shore or within a certain period of the day, depending on biotic and abiotic constraints (Little 1989, Chapman \& Underwood 1992). Temporally, animals may be active when submerged, emersed or awash on rising or falling tides; some animals forage only during the day or at night-time, whereas others are active regardless of the diel cycle (Little 1989). These activity patterns are thought to help grazers avoid a suite of unfavourable environmental constraints, such as wave dislodgement (Mackay \& Underwood 1977), desiccation (Cook \& Cook 1981, Branch \& Cherry 1985) and thermal stress (Garrity 1984), as well as biotic interactions, mainly competition and predation (Levings \& Garrity 1984, Branch \& Cherry 1985).

However, the behaviour of some species does not conform to rigid classification, and the temporal organization of their activities is extremely labile (e.g. Siphonaria capensis, Branch \& Cherry 1985; Patella vulgata, Little et al. 1991; Helcion pectunculus, Gray \& Hodgson 1999). This variation has been linked to dif- 
ferent possible causal factors, for instance, rainfall, wave splash, shore height and rock slope, which create different favourable or unfavourable conditions for grazers to respond to (Williams \& Morritt 1991, Williams et al. 1999, Santini et al. 2004). Such variability illustrates the dangers of over-generalizing spatial and temporal organization of activity and the importance of studying intraspecific, i.e. between individuals on the same shore, variability in foraging behaviour. In addition, even though endogenous rhythms synchronized with a certain periodicity of the natural environment by an internal clock (Enright 1970, Palmer 1995) may control general activity patterns of many species, these rhythms can be overridden, further contributing to variation in a species' basic behavioural rhythms (Williams \& Morritt 1995, Gray \& Hodgson 1999). Activity patterns may, for example, vary with season (Della Santina et al. 1995), size (Takada 2001), height on the shore (Little \& Stirling 1985, Williams \& Morritt 1991, Santini et al. 2004) and microhabitat (Della Santina \& Chelazzi 1991). Intraspecific variability has been linked to the effects of desiccation, predation, competition and the availability of food resources (Little \& Stirling 1985, Della Santina et al. 1995), such that the behavioural strategies of each individual may be shaped differently by the small-scale environmental factors (micro-environment) each experiences (Williams \& Morritt 1991). However, information on such intraspecific variability is mostly qualitative, as this information is lost when data from each individual is pooled for analysis. Understanding what causes intraspecific variability may be key to understanding the precise determinants of activity patterns of intertidal animals.

Hong Kong has a strongly seasonal climate and a narrow tidal range ( 2.5 m, Kaehler \& Williams 1996). Under such a physically stressful environment (Kaehler \& Williams 1996), many grazers migrate downshore in summer (Harper \& Williams 2001) and limit their distribution when emersed to refuges such as cracks, crevices and rock pools (Williams \& Morritt 1995, Hutchinson \& Williams 2003). However, the chiton, Acanthopleura japonica (Lischke, 1873), does not show seasonal vertical migration and maintains a wide vertical range throughout the year $(0.25$ to $1.75 \mathrm{~m}$ above chart datum [CD], Harper \& Williams 2001). Therefore, individuals of A. japonica at different shore heights may experience unique environmental conditions specific to their location. This study adopts an individual approach to investigate the temporal organization of activity and rhythmic behaviour of A. japonica at different resting shore heights, under different tidal conditions and in different seasons. Specifically, it tests whether individuals exhibit variation in daily foraging patterns and duration to suit their local micro-environments, resulting in different foraging strategies.

\section{MATERIALS AND METHODS}

Hong Kong climate. The tropical, monsoonal climate of Hong Kong results in strong seasonality (Kaehler \& Williams 1996). The hot, wet summer (June to September) has high temperatures (maximum air temperature $\sim 36^{\circ} \mathrm{C}$, monthly mean $\sim 28^{\circ} \mathrm{C}$; monthly mean sea surface temperature $\sim 27^{\circ} \mathrm{C}$, Hong Kong Observatory [HKO]) and heavy rainfall (monthly mean $\sim 348 \mathrm{~mm}$, HKO), whereas the cool, dry winter (December to March) has monthly mean air and sea surface temperatures of $\sim 17$ and $\sim 18^{\circ} \mathrm{C}$ respectively, with little rainfall ( 41 mm, HKO). The tidal pattern is complex, with a transition from semi-diurnal, mixed spring tides to semi-diurnal, or sometimes diurnal, neap tides (Morton et al. 1996). Extreme low tides occur after midnight in winter, but during the afternoon in summer, when they are $\sim 0.6 \mathrm{~m}$ lower than winter (Kaehler \& Williams 1996). In general, wave action is higher in winter, except during typhoons in summer (Morton et al. 1996).

Activity pattern of Acanthopleura japonica. Observations were conducted along a $15 \mathrm{~m}$ stretch of moderately exposed, southeast-facing rocky shore (S4, Kaehler \& Williams 1996) at Cape d'Aguilar, Hong Kong $\left(22^{\circ} 15^{\prime} \mathrm{N}, 114^{\circ} 10^{\prime} \mathrm{E}\right)$, from July 2003 to March 2004. Early each season (June and December) all individuals with a fifth-plate length $>10 \mathrm{~mm}$ (i.e. reproductively mature individuals, Harper 1996) from 0.5 to $1.25 \mathrm{~m}$ above CD were tagged during low tide with numbered micromarkers (Brady USA).

Activity was monitored for twelve $24 \mathrm{~h}$ periods: 3 during spring tides and 3 during neap tides in each season $(\Sigma n=2$ seasons $\times 2$ tidal conditions $\times 3$ days $=$ 12). At each observation, the activity of $>30$ randomly selected chitons from different shore heights (highshore: 1.0 to $1.25 \mathrm{~m}$; mid-shore: 0.75 to $1.0 \mathrm{~m}$; lowshore: 0.5 to $0.75 \mathrm{~m}$ above $\mathrm{CD}$ ) was recorded at 30 or 60 min intervals, during active or inactive periods respectively. Activity was defined as visible movement for $15 \mathrm{~s}$, with underwater observations being conducted by snorkeling and observations at night assisted with red light to reduce disturbance (Little \& Stirling 1985).

The total percentage of active individuals and the percentage from the 3 heights at each time interval were calculated for each observation. The time of modal activity peak at each height was compared with the tidal curve by cross-correlation, to investigate how percentage activity changed with tide. Similarities in chiton-activity patterns were visualized by 
non-metric multidimensional scaling (nMDS) using Bray-Curtis coefficient matrices (PRIMER v6, Clarke \& Warwick 2001). Differences in activity patterns were compared between seasons and tidal conditions by 2-way crossed, permutation-based analysis of similarity (ANOSIM) on untransformed data.

Ten individuals were randomly chosen from each shore height to analyze the daily duration of activity, which was compared between seasons (2 levels; fixed and orthogonal), tidal conditions (2 levels; fixed and orthogonal), shore heights (3 levels; fixed and orthogonal), observation days ( 3 days; random and nested under season and tidal condition) and any interactions among these factors by a 4 -factor, mixed-model analysis of variance (ANOVA).

Intraspecific variability in temporal organization of activity at different shore heights was examined in each season. Within their active period, the fraction of activity during day/night (i.e. fraction of daytime activity + fraction of night-time activity $=1$ ) and on ebbing/ flooding tides (i.e. fraction of activity on flooding tides + fraction of activity on ebbing tides $=1$ ) was analyzed for 30 different individuals which had been tracked for at least 2 spring and 2 neap tide days. The temporal organization of activity, expressed as the fraction of activity at night and on flooding tides, was established for each individual. Intraspecific variability was determined by comparing the predominance of individuals' activity during day/night and on ebbing/flooding tides.

Endogenous rhythms of activity in Acanthopleura japonica. Ten animals (mean fifth-plate length $\sim 18 \mathrm{~mm}$ ) from each shore height (high-, mid- and lowshore) were collected on an ebbing tide and transferred to the laboratory within $1 \mathrm{~h}$, placed in separate tanks $(80 \mathrm{~cm} \times 40 \mathrm{~cm} \times 16 \mathrm{~cm} ; L \times W \times H)$, and isolated from day/night or tidal cycles and daily temperature fluctuations. Activity was recorded by time-lapse videography (WV-BP310 camera and AG-6040 timelapse VCR, Panasonic) for $72 \mathrm{~h}$, in constant darkness with an infrared light source while animals were sprayed continuously with fresh seawater. The number of active chitons from each shore height was recorded in 30 min bins from the video recordings.

Rhythmicity in activity of individuals from the 3 shore heights was evaluated by auto-correlation, with subsequent period estimation performed by maximum entropy spectral analysis (MESA, Levine et al. 2002). Such combination of tests allows the calculation of statistical confidence intervals to evaluate true rhythmicity (H. B. Dowse pers. comm.). Whenever similar periods were estimated for chitons from different shore heights, the phase difference between the respective heights was compared by running cross-correlations of data from 1 height against a benchmark dataset with sinusoidal waves and known period.

\section{RESULTS}

\section{Activity pattern of Acanthopleura japonica}

\author{
General pattern
}

Acanthopleura japonica was active while awash either on flooding or ebbing tides and inactive during submergence and emersion, regardless of day-night changes (Fig. 1). During spring tides in both seasons, when the tide began to recede, 2 activity peaks were found on the lower low tide which occurred in the afternoon in summer but after midnight in winter, each peak coinciding with the ebbing and rising tides, respectively. Another peak occurred during the other, higher low tide when some animals were awash. There were only 2 activity peaks on neap tides in both seasons, one at the time of each low tide when the animals were awash. Higher percentages of activity usually occurred at the lower of the 2 low tides. Animals were inactive when submerged during high tides. Daily activity patterns of chitons were significantly different between seasons and tidal conditions (Fig. 2) (2-way crossed ANOSIM between seasons: $\mathrm{R}=0.352, \mathrm{p}=0.001$; between tidal conditions: $\mathrm{R}=$ $0.354, \mathrm{p}=0.001$ ).

\section{Small-scale pattern—shore height differences}

Individuals from high-, mid- and low-shores showed predictable, but asynchronous activity patterns, with a clear lag phase between different heights on spring and neap tides during both summer and winter (Fig. 1). As the tide receded, high-shore chitons became active first, followed by mid-shore chitons and finally those of the low-shore. On the rising tide, the activity of lowshore chitons decreased first, followed by mid-shore chitons and finally those of the high-shore. Activity from all shore heights was inversely in phase with tide, i.e. peaks of activity were coupled with low tides and inactivity with high tides (mean cross-correlation coefficients $=-0.014$ to -0.040 at lag $=0 \mathrm{~h}$ ), except for the activity of high-shore chitons on summer spring tides, which was in phase with tide (mean cross-correlation coefficient $=0.010$ at lag 0 ).

Although the timing and intensity of activity varied with daily and tidal conditions, high-shore chitons generally showed greater activity on the higher of the 2 low tides under both tidal conditions and seasons (Fig. 1). The activity patterns of mid- and low-shore chitons were similar, with the greatest activity associated with the lower of the 2 low tides (Fig. 1). The number of peaks shown by chitons from all heights was dependent on the tidal range of a particular day. 
Tidal level (m above CD)
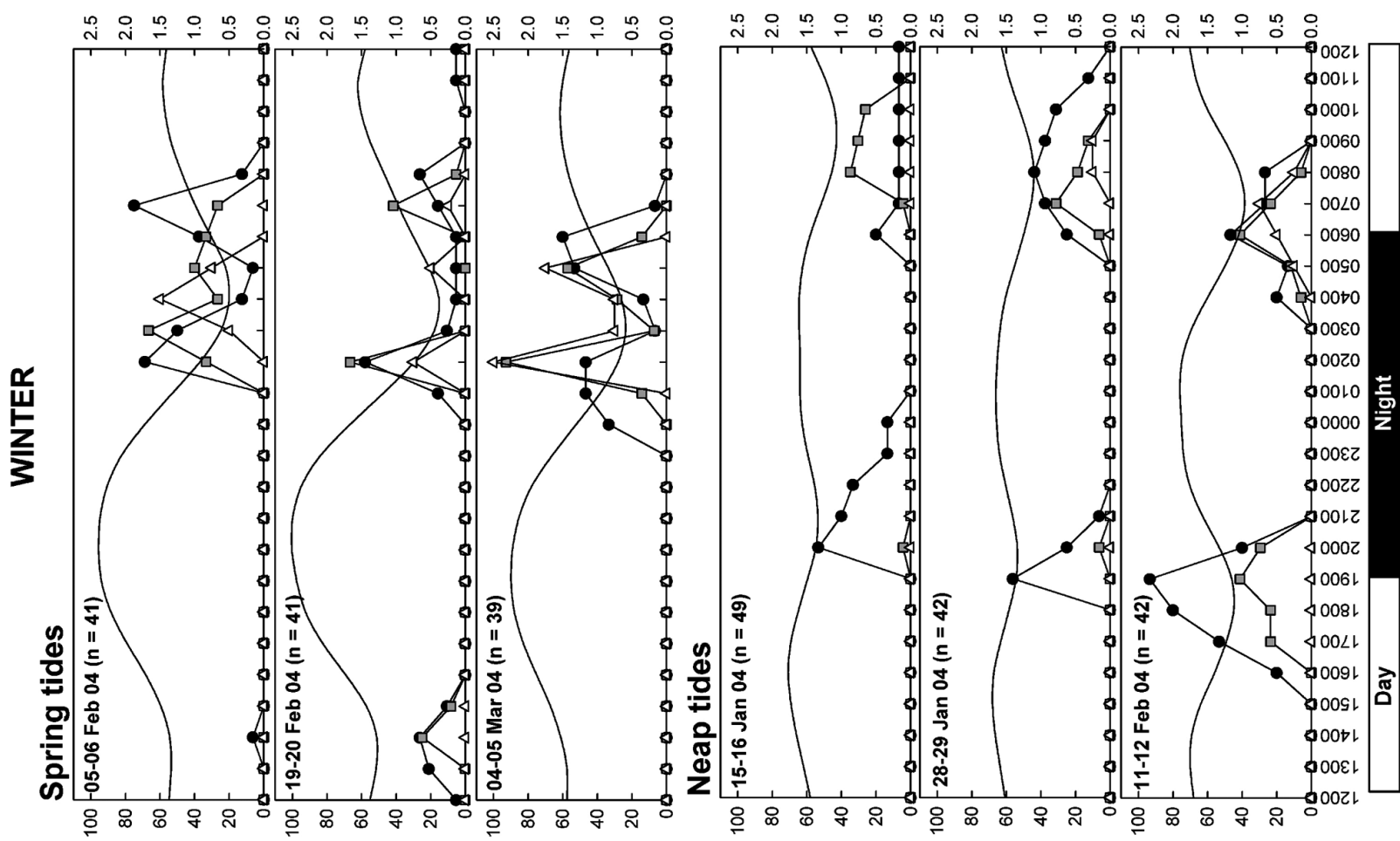

$\stackrel{\pi}{\pi}$

\section{Active individuals (\%)}

Tidal level ( $m$ above $C D$ )

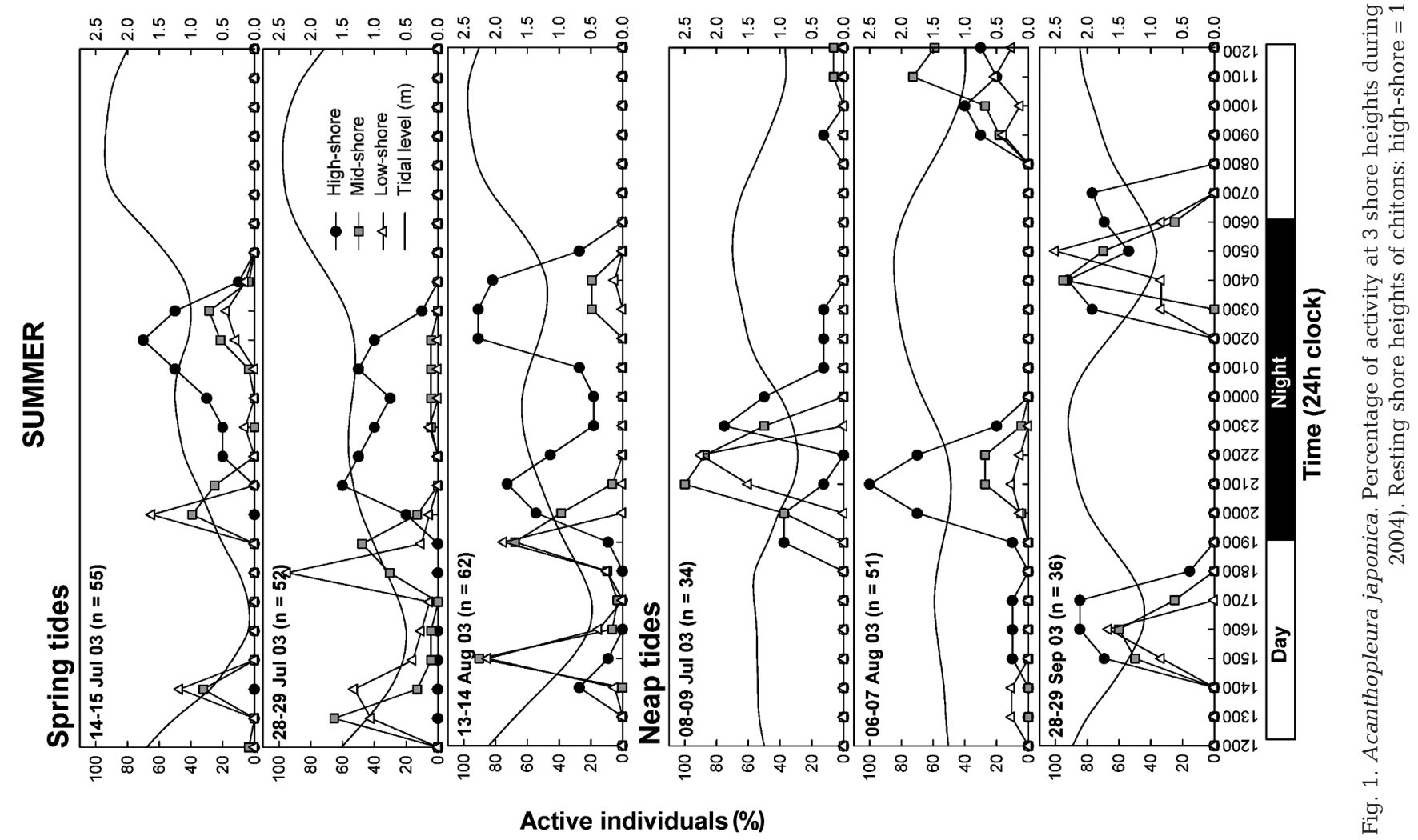




\section{Duration of activity}

Chitons were active for longer in summer than winter, although there was no clear difference in the number of hours active per day between spring and neap tides (Fig. 3, Table 1). A clear vertical gradient in the number of hours active was seen, with high-shore chitons having the longest activity duration, followed by mid-shore chitons and finally those of the low-shore (Fig. 3, Table 1).

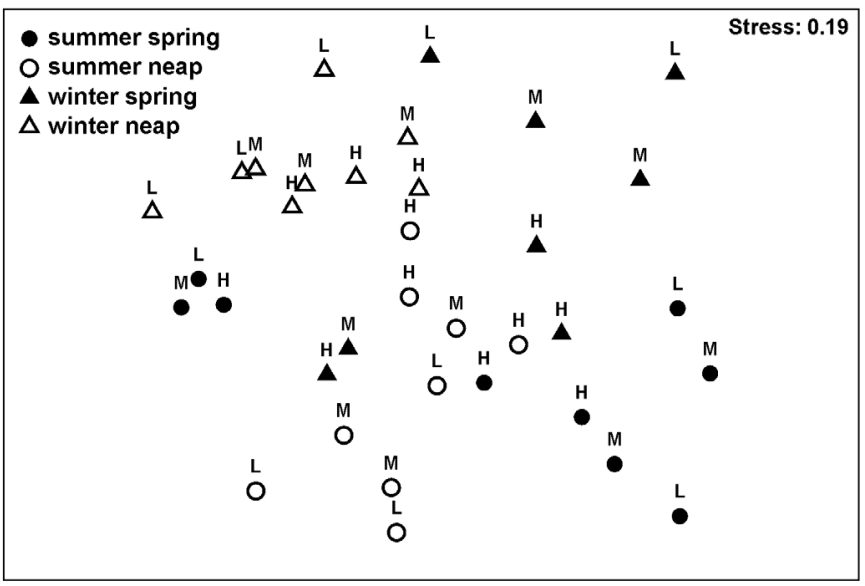

Fig. 2. Acanthopleura japonica. nMDS plot of activity patterns at 3 shore heights during spring and neap tides in summer (July to September 2003) and winter (January to March 2004) (n = 3 d). H, $\mathrm{M}$ and L denote patterns of high-, mid- and low-shore chitons, respectively
Daily effects on activity duration were recorded between dates (Fig. 3), and interacted with season and tidal condition at the different heights $(\mathrm{Hg} \times \mathrm{Da}[\mathrm{Se} \times$ $\mathrm{T}$ ], Table 1). The duration of activity of chitons from different shore heights could, for example, either be lower (e.g. mid-shore chitons on 28 to 29 January, Fig. 3) or higher (e.g. low-shore chitons on 28 to 29 July, Fig. 3) on some dates than others within the same tidal condition and season.

Comparison of the observed duration of activity against the observed duration of the awash period, i.e. the chitons' potential foraging window, showed that Acanthopleura japonica spent less time foraging than the potential time window available in both seasons (Fig. 4). Activity duration in winter was only $~ 35 \%$ of the potential foraging window. However, in summer some individuals did maximize their foraging duration, foraging for $\sim 75 \%$ of the duration of the awash period.

\section{Intraspecific variability in activity}

There was a high degree of variability in the timing of activity between chitons from different shore heights, and also within each shore height, at different times of the year (Fig. 5). In summer, high-shore chitons foraged more on night-time, flooding tides, spending $>65 \%$ of their activity at night and 46 to $74 \%$ on the flooding tide (Fig. 5). However, activity of mid- and low-shore chitons was more variable: individuals spent 39 to $100 \%$ of their activity during day-
SUMMER

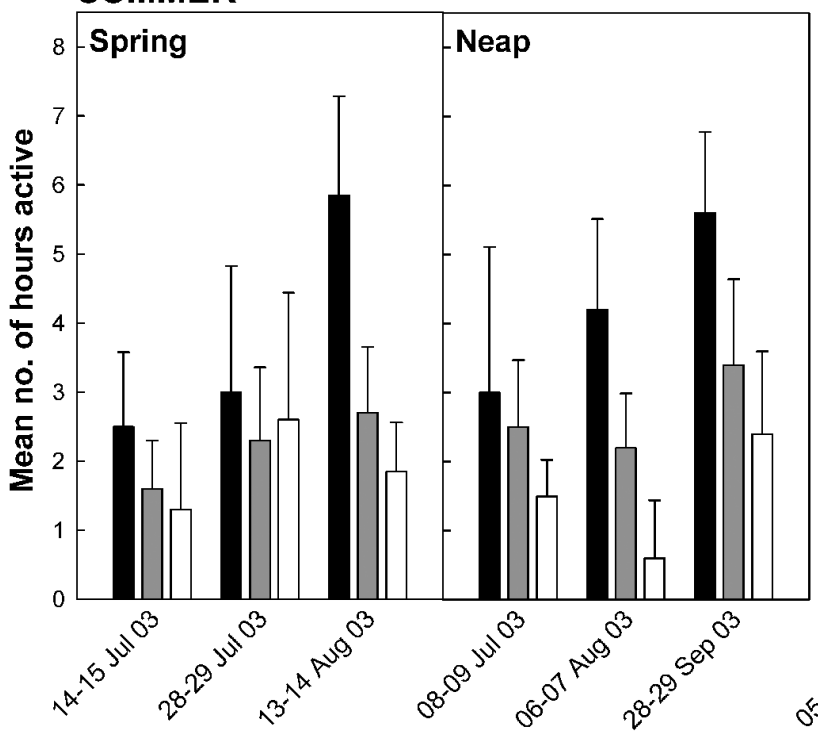

\section{WINTER}

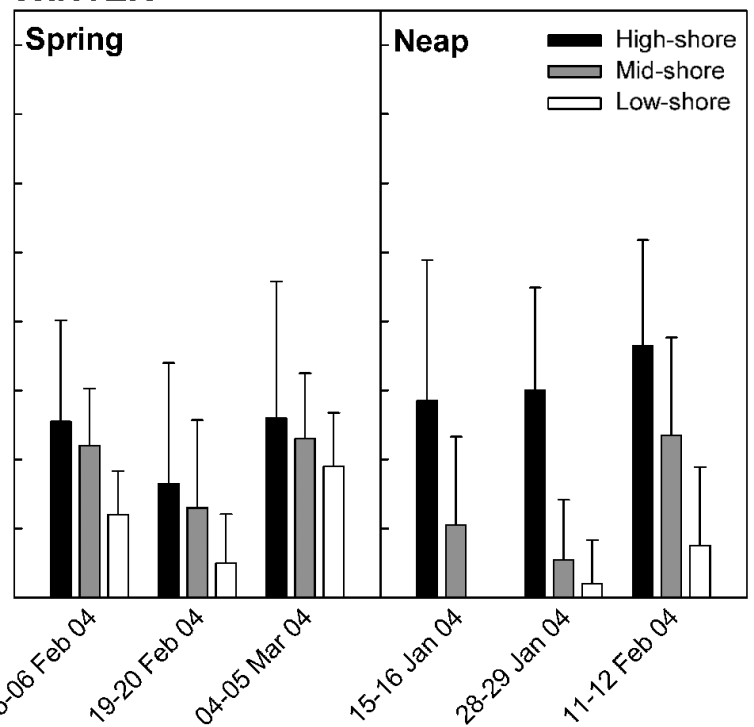

Fig. 3. Acanthopleura japonica. Hours of activity of individuals at 3 shore heights during spring and neap tides in summer (July to September 2003) and winter (January to March 2004) (mean + SD) 
time and 26 to $83 \%$ on flooding tides (Fig. 5). All but 1 individual from all shore heights spent $>50 \%$ of their activity period at night in winter (Fig. 5), and activity was, in general, shared between ebbing and flooding tides in winter (35 to $70 \%$ on flooding/ebbing tides), although some individuals spent as little as $29 \%$, or as much as $100 \%$, of their activity period during flooding tides.

\section{Endogenous rhythms of activity in Acanthopleura japonica}

Peak percentages of activity in the laboratory under constant conditions were usually $>70 \%$ for chitons from all shore heights. Most individuals were active when awash on the shore, and the time of reduced activity coincided with

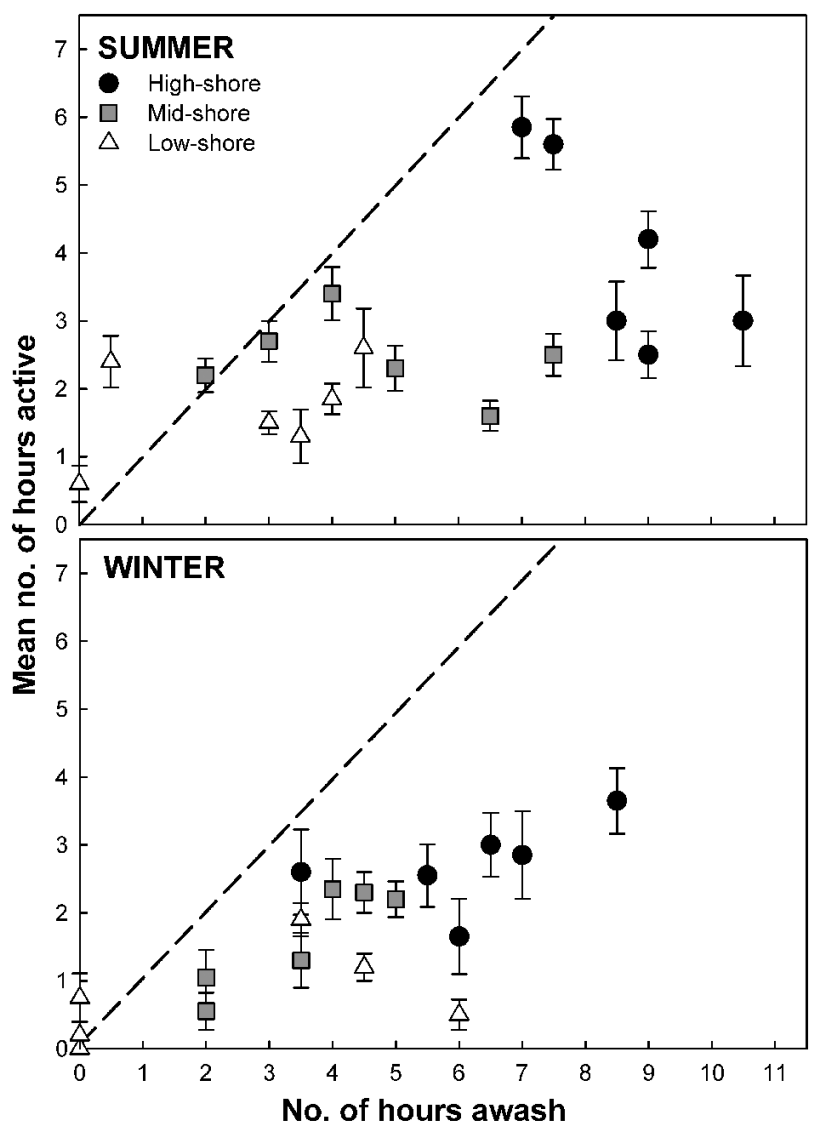

Fig. 4. Acanthopleura japonica. Hours of activity of individuals at 3 shore heights $(\mathrm{n}=30)$ and hours awash in summer (July to September 2003) and winter (January to March 2004) (mean $\pm \mathrm{SE}$ ). Dashed lines represent isoclines, i.e. hours active $=$ hours awash
Table 1. Acanthopleura japonica. Comparison of daily duration of activity between seasons (Se), tidal conditions (Ti), day (Da) nested in season and tidal condition, and shore heights $(\mathrm{Hg})$ using a 4 -factor, mixed-model ANOVA ( $\mathrm{n}=$ 10). Variances were homogeneous: Cochran's test, $C=0.079(p>0.05)$. Significant differences are shown in bold

\begin{tabular}{|lrrrrl}
\hline Source & df & \multicolumn{1}{c}{ MS } & \multicolumn{1}{c}{$F$} & \multicolumn{1}{c}{ p } & \multicolumn{1}{c}{$F$ versus } \\
\hline $\mathrm{Se}$ & 1 & 95.07 & 6.14 & $\mathbf{0 . 0 3 8}$ & $\mathrm{Da}(\mathrm{Se} \times \mathrm{Ti})$ \\
$\mathrm{Ti}$ & 1 & 0.00 & 0.00 & 0.990 & $\mathrm{Da}(\mathrm{Se} \times \mathrm{Ti})$ \\
$\mathrm{Da}(\mathrm{Se} \times \mathrm{Ti})$ & 8 & 15.49 & 9.92 & $<\mathbf{0 . 0 0 1}$ & Residual \\
$\mathrm{Hg}$ & 2 & 139.87 & 37.66 & $\mathbf{< 0 . 0 0 1}$ & $\mathrm{Hg} \times \mathrm{Da}(\mathrm{Se} \times \mathrm{Ti})$ \\
$\mathrm{Se} \times \mathrm{Ti}$ & 1 & 3.40 & 0.22 & 0.652 & $\mathrm{Da}(\mathrm{Se} \times \mathrm{Ti})$ \\
$\mathrm{Se} \times \mathrm{Hg}$ & 2 & 1.89 & 0.51 & 0.611 & $\mathrm{Hg} \times \mathrm{Da}(\mathrm{Se} \times \mathrm{Ti})$ \\
$\mathrm{Ti} \times \mathrm{Hg}$ & 2 & 13.56 & 3.65 & $\mathbf{0 . 0 4 9}$ & $\mathrm{Hg} \times \mathrm{Da}(\mathrm{Se} \times \mathrm{Ti})$ \\
$\mathrm{Hg} \times \mathrm{Da}(\mathrm{Se} \times \mathrm{Ti})$ & 16 & 3.71 & 2.38 & $\mathbf{0 . 0 0 2}$ & $\mathrm{Residual}$ \\
$\mathrm{Se} \times \mathrm{Ti} \times \mathrm{Hg}$ & 2 & 4.44 & 1.20 & 0.328 & $\mathrm{Hg} \times \mathrm{Da}(\mathrm{Se} \times \mathrm{Ti})$ \\
Residual & 324 & 1.56 & & & \\
& & & & & \\
\hline
\end{tabular}

the expected high tide during the day, when animals would be submerged. The intensity of activity remained quite strong at the end of the experiment $(72 \mathrm{~h})$, indicating the strength and persistence of the endogenous rhythm in Acanthopleura japonica. Chitons from high-, mid- and low-shore had a strongly rhythmic activity (auto-correlation coefficients $=0.39$, 0.41 and 0.40 , respectively), with periods of 22.40, 26.38 and $25.25 \mathrm{~h}$, respectively. When compared with a benchmark dataset, the activity of high- and mid-shore chitons indicated no phase differences (cross-correlation coefficients $=0.021$ and 0.012 , respectively, at lag $=0 \mathrm{~h}$ ). However, activity of low-shore chitons showed a $2 \mathrm{~h}$ phase difference with that of highand mid-shore chitons (cross-correlation coefficients = 0.028 at $\operatorname{lag}=2 \mathrm{~h}$ ).

\section{DISCUSSION}

\section{Activity patterns - general and small-scale shore height differences}

This study confirms that Acanthopleura japonica is an awash-feeder (Harper 1996), similar to other gastropods on tropical shores (Panama, Garrity 1984; Hong Kong, Hutchinson \& Williams 2003). Activity is predominantly controlled by tidal movement rather than the diel cycle. Being active while awash is perhaps the best strategy to take advantage of favourable environmental conditions (Garrity 1984, Little 1989), as being inactive in refuges during emersion reduces desiccation and thermal stress (Cook \& Cook 1981, Garrity 1984, Branch \& Cherry 1985). Inactivity during submergence may also protect against wave dislodgement (Branch \& Cherry 1985, Gray \& Hodgson 1997) and marine predators (Levings \& Garrity 1984). 


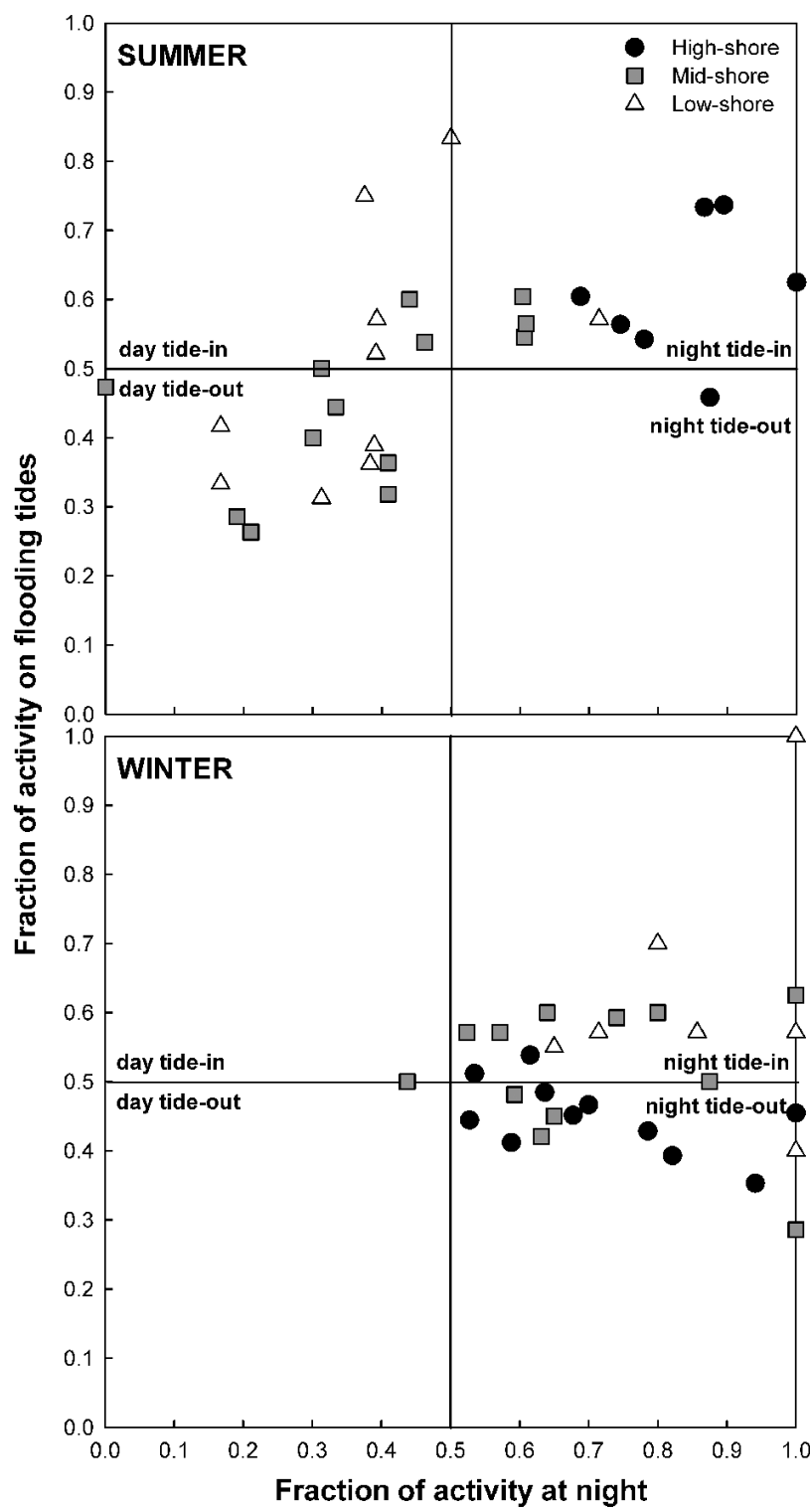

Fig. 5. Acanthopleura japonica. Temporal partitioning of activity of selected individuals $(\mathrm{n}=30)$ in summer (July to September 2003) and winter (January to March 2004). Each point indicates the mean value from 1 individual. Splits at fraction = 0.5 represent equal fractions of activity spent during daytime and night-time or on ebbing and flooding tides

Intense activity peaks were found on summer afternoons, but after midnight in winter, associated with variation in the timing of low tides. The major activity window of Acanthopleura japonica coinciding with awash periods during these low tides suggests that seasonal and day-night influences are minimal and overridden by the tidal cycle (Hirano 1979). Intrinsic differences in the Hong Kong tidal pattern also explain the observed variation in activity between spring and neap tides in both seasons. Most chitons were emersed and activity ceased at the time of the lower low tide only on spring tides, resulting in 2 activity peaks, each corresponding to the ebbing and rising tides during this low tide, instead of only 1 peak on neap tides.

The timing of activity of high-, mid- and low-shore chitons reflected their first wave splash, which wets low-shore chitons first on rising tides, and high-shore chitons first on ebbing tides. Such a delayed effect with shore height produces a lag phase of activity corresponding to respective awash periods, and therefore the cessation or onset of activity of chitons from different shore heights follows a predictable sequence.

\section{Duration of activity - foraging strategies exhibited by different individuals}

Chitons were active for significantly longer in summer than winter, probably due to different physiological and behavioural responses of individuals. Metabolic rate, and hence activity, may slow down with decreasing air and seawater temperatures in winter. The limpet Patella granularis for example, travelled almost 3 times shorter distances in the cooler winter than summer (Gray \& Hodgson 1997). However, reduction in activity in winter is counterintuitive, considering that foraging should be positively correlated with greater wave action in winter (Harper 1996, this study). Acanthopleura japonica remains relatively inactive in winter, perhaps adopting a time-minimization strategy (see Evans \& Williams 1991). A longer foraging time may be needed in summer to ingest the same amount of food to meet basic energetic requirements (see Chapman \& Underwood 1992, Della Santina et al. 1995), as food is less abundant than in winter (Nagarkar \& Williams 1999). The topshell, Monodonta labio, has also been suggested to feed for longer in summer due to low algal abundance (Takada 2001). Therefore, energy maximization is a better strategy in summer (see Evans \& Williams 1991). However, duration of activity was similar on spring and neap tides, probably as differences in environmental temperatures, wave action or standing crop on this time scale were minimal.

Duration of activity decreased from high- to mid- to low-shore chitons, regardless of seasonal or tidal condition. The relatively small tidal amplitude in Hong Kong allows a long awash period for high-shore chitons, whereas mid- and low-shore chitons spend more time submerged. Therefore, high-shore chitons will spend more time foraging which may help maximize their energy intake during this relatively wide foraging window. Food is also more abundant lower on the shore (Nagarkar \& Williams 1999), which may allow low-shore chitons to attain a sufficient food supply in a 
shorter time, i.e. time minimization (Chapman \& Underwood 1992, Takada 2001).

\section{Daily variation in activity}

The large day-to-day variation in the number of activity peaks, percentage of individuals active and duration of activity for chitons from all shore heights was probably associated with daily variation in atmospheric pressure, wind speed and direction and duration of bright sunshine. These environmental changes affect the tidal range, the timing and duration of the awash period and also the heat stress animals experience on each day, modifying their potential foraging windows. In both summer and winter, for example, strong easterly winds (28 to 29 September and 4 to 5 March, HKO) brought higher wave wash for longer periods, initiating activity and prolonging awash periods, and the highest activity peaks and the longest activity duration were recorded on these days. However, intense sunshine on 14 July with calm seas resulted in lower activity peaks than on other spring days in summer, and the shortest activity duration. In contrast, activity peaks were higher and activity was longer on 13 to 14 August, which was cloudy and rainy. Many intertidal animals modify their behaviour in response to weather conditions, for example, activity of Nucella lapillus is limited during sunny, calm days on sheltered shores (Burrows \& Hughes 1989). Such daily variation in activity duration demonstrates that Acanthopleura japonica is highly opportunistic, adjusting its foraging behaviour in response to environmental changes.

\section{Intraspecific variability in foraging behaviour}

In summer, high-shore Acanthopleura japonica showed a high proportion of night-time activity, possibly to avoid thermal and desiccation stress during daytime low tides. However, low- and mid-shore chitons may have become submerged and therefore were inactive during the higher low tide at night. This reduces their time available to forage and, as a result, drives some of these animals to forage more during the daytime low tide, as also suggested for low-shore Patella vulgata (Williams \& Morritt 1991). Conversely, in winter, a higher proportion of activity was found at night for animals from all shore heights. The higher average wave height in winter (Morton et al. 1996) means that the higher, midday low tide may submerge most chitons. Therefore, activity is associated more strongly with the lower, night-time low tide which allows a longer awash period for activity. Marked intraspecific variability in the temporal organization of activity has been recognized in the littorinid Littorina unifasciata (Chapman 2000), and the limpet P. vulgata which shows variable behaviour at different heights on the shore (Little \& Stirling 1985, Williams \& Morritt 1991, Santini et al. 2004) and on shores with different slopes (Williams et al. 1999, Santini et al. 2004). As A. japonica from different shore heights stay at that particular height throughout the year (Harper 1996, J.S.S. $\mathrm{Ng}$ unpubl. data), they experience micro-environments specific to their heights in different seasons and have different foraging windows, and therefore they develop specific, corresponding activity and behavioural patterns (Della Santina \& Chelazzi 1991, Coleman et al. 2004). Intraspecific behavioural variation may be the result of complex interactions among factors such as food availability, changes in physiological stress, energetics and reproductive state (Della Santina \& Chelazzi 1991, Hughes \& Burrows 1994, Della Santina et al. 1995, Santini et al. 2004), which will vary with season or height on the shore (Santini et al. 2004).

\section{Endogenous versus exogenous control of activity}

Acanthopleura japonica exhibited a circalunidian (lunar-daily) periodicity, which enables the animals to gauge or time their foraging window and ensures that individuals are only active during the awash period. Such a rhythm has been widely recorded in intertidal decapods (Palmer 1995) and seems to be more appropriate than a purely circatidal rhythm, mainly because A. japonica experiences both mixed, semi-diurnal and diurnal tides, but also because the timing and duration of the awash period is variable. The synchronization of activity rhythms with major environmental cycles is considered to be highly adaptive, allowing resources to be optimally utilized and unfavourable, if not lethal, stress to be avoided (Palmer 1995, Gray \& Hodgson 1999). Although entrainment zeitgebers were not identified, activity is likely to be initiated by the first wave splash and the associated changes in physical properties, e.g. temperature, salinity or pressure changes (Palmer 1995). A. japonica probably only has a single clock to govern its endogenous rhythmicity, and while the observed periods did not exactly match a lunar day (i.e. $24.82 \mathrm{~h}$ ), such minor deviations are common in other intertidal organisms (Palmer 1995). Phase differences in low-shore chitons were evident, again showing that the timing of first awash is important in controlling endogenous rhythms in A. japonica. Similar to the limpets Patella vulgata (Della Santina et al. 1995) and Helcion pectunculus (Gray \& Hodgson 1999), the endogenous rhythm in A. japonica can be overridden by exogenous factors, as activity can be initiated or 
prolonged when animals are awash more times on mixed tides, or for longer during storms when wave action is greater, resulting in more than 1 activity peak in a lunar day.

Variability in the foraging behaviour of intertidal grazers occurs from place to place and time to time, and it reflects the adaptive changes of populations to both broad-scale and localized environmental conditions. Acanthopleura japonica has a clear, overall pattern of activity which differs between seasons and tidal conditions. However, from summer to winter and from high- to mid- to low-shore, A. japonica varies its foraging strategies from possible energy-maximizing to time-minimizing strategies. The plasticity in different foraging strategies adopted by A. japonica in different seasons and at different shore heights is presumably a response to confer advantages to individuals by optimizing their foraging success in spatially and temporally variable environments.

Acknowledgements. The authors are extremely grateful to Prof. Harold B. Dowse (University of Maine, USA) for advice in rhythm analysis, and to Steve and Karen Lui and Maggie, Avis and Karen Qiu for excellent field assistance. This research was conducted in partial fulfilment of a $\mathrm{PhD}$ degree by J.S.S.N., who is supported by a postgraduate studentship at The University of Hong Kong. Permission to work in the Cape d'Aguilar Marine Reserve was granted by the Agriculture, Fisheries and Conservation Department, HKSAR Government. We thank Prof. Peter Petraitis, 3 anonymous reviewers and the Hard Rock Ecology Group (HKU) for useful comments on the manuscript.

\section{LITERATURE CITED}

Branch GM, Cherry MI (1985) Activity rhythms of the pulmonate limpet Siphonaria capensis Q. \& G. as an adaptation to osmotic stress, predation and wave action. J Exp Mar Biol Ecol 87:153-168

Burrows MT, Hughes RN (1989) Natural foraging of the dogwhelk, Nucella lapillus (Linnaeus); the weather and whether to feed. J Molluscan Stud 55:285-295

Chapman MG (2000) Variability of foraging in highshore habitats: dealing with unpredictability. Hydrobiologia 426:75-87

Chapman MG, Underwood AJ (1992) Foraging behaviour of marine benthic grazers. In: John DM, Hawkins SJ, Price JH (eds) Plant-animal interactions in the marine benthos. Clarendon Press, Oxford, p 289-317

Clarke KR, Warwick RM (2001) Change in marine communities: an approach to statistical analysis and interpretation, 2nd edn. PRIMER-E, Plymouth

Coleman RA, Underwood AJ, Chapman MG (2004) Absence of costs of foraging excursions in relation to limpet aggregation. J Anim Ecol 73:577-584

Cook SB, Cook CB (1981) Activity patterns in Siphonaria populations: heading choice and the effects of size and grazing interval. J Exp Mar Biol Ecol 49:69-79

Della Santina P, Chelazzi G (1991) Temporal organization of foraging in two Mediterranean limpets, Patella rustica L. and P. coerulea L. J Exp Mar Biol Ecol 153:75-85

Della Santina P, Santini G, Chelazzi G (1995) Factors affecting variability of foraging excursions in a population of the limpet Patella vulgata (Mollusca, Gastropoda). Mar Biol 122:265-270

Enright JT (1970) Ecological aspects of endogenous rhythmicity. Annu Rev Ecol Syst 1:221-238

Evans MR, Williams GA (1991) Time partitioning of foraging in the limpet Patella vulgata. J Anim Ecol 60:563-575

Garrity SD (1984) Some adaptations of gastropods to physical stress on a tropical rocky shore. Ecology 65:559-574

Gray DR, Hodgson AN (1997) Temporal variation in foraging behaviour of Patella granularis (Patellogastropoda) and Siphonaria concinna (Basommatophora) on a South African shore. J Molluscan Stud 63:121-130

Gray DR, Hodgson AN (1999) Endogenous rhythms of locomotor activity in the high-shore limpet, Helcion pectunculus (Patellogastropoda). Anim Behav 57:387-391

Harper KD (1996) The ecology of Acanthopleura japonica (Mollusca: Polyplacophora): a dominant herbivore on Hong Kong rocky shores. PhD dissertation, The University of Hong Kong

Harper KD, Williams GA (2001) Variation in abundance and distribution of the chiton Acanthopleura japonica and associated molluscs on a seasonal, tropical, rocky shore. J Zool Lond 253:293-300

Hawkins SJ, Hartnoll RG (1983) Grazing of intertidal algae by marine invertebrates. Oceanogr Mar Biol Annu Rev 21: $195-282$

Hirano Y (1979) Studies on activity pattern of the patellid limpet Cellana toreuma (Reeve). J Exp Mar Biol Ecol 40: $137-148$

Hughes RN, Burrows MT (1994) An interdisciplinary approach to the study of foraging behaviour in the predatory gastropod, Nucella lapillus (L.). Ethol Ecol Evol 6: $75-85$

Hutchinson N, Williams GA (2003) An assessment of variation in molluscan grazing pressure on Hong Kong rocky shores. Mar Biol 142:495-507

Kaehler S, Williams GA (1996) Distribution of algae on tropical rocky shores: spatial and temporal patterns of noncoralline encrusting algae in Hong Kong. Mar Biol 125: $177-187$

Levine J, Funes P, Dowse HB, Hall J (2002) Signal analysis of behavioral and molecular cycles. Biomed Central Neurosci 3:1-25

Levings SC, Garrity SD (1984) Grazing patterns in Siphonaria gigas (Mollusca, Pulmonata) on the rocky Pacific coast of Panama. Oecologia 64:152-159

Little C (1989) Factors governing patterns of foraging activity in littoral marine herbivorous molluscs. J Molluscan Stud $55: 273-284$

Little C, Stirling P (1985) Patterns of foraging activity in the limpet Patella vulgata L. - a preliminary study. J Exp Mar Biol Ecol 89:283-296

Little C, Partridge J, Teagle L (1991) Foraging activity of limpets in normal and abnormal tidal regimes. J Mar Biol Assoc UK 71:537-554

Mackay DA, Underwood AJ (1977) Experimental studies on homing in the intertidal Patellid limpet Cellana tramoserica (Sowerby). Oecologia 30:215-237

Morton BS, Williams GA, Lee SY (1996) The benthic marine ecology of Hong Kong: a dwindling heritage? In: Civil Engineering Department (ed) Coastal infrastructure development in Hong Kong: a review. Hong Kong Government, Hong Kong, p 233-267

Nagarkar S, Williams GA (1999) Spatial and temporal varia- 
tion of cyanobacteria-dominated epilithic communities on a tropical shore in Hong Kong. Phycologia 38:385-393

Palmer JD (1995). The biological rhythms and clocks of intertidal animals. Oxford University Press, New York

Santini G, Thompson RC, Tendi C, Hawkins SJ, Hartnoll RG, Chelazzi G (2004) Intra-specific variability in the temporal organization of foraging activity in the limpet Patella vulgata. Mar Biol 144:1165-1172

Takada Y (2001) Activity patterns of the herbivorous gastropod Monodonta labio on a boulder shore at Amakusa, Japan. Venus 60:15-25

Editorial responsibility: Howard I. Browman (Associate Editor-in-Chief), Storebø, Norway
Williams GA, Morritt D (1991) Patterns of foraging in Patella vulgata (L.). In: Myers A, Little C, Costello M, Partridge J (eds) The ecology of Lough Hyne. Royal Irish Academy, Dublin, p 61-69

Williams GA, Morritt D (1995) Habitat partitioning and thermal tolerance in a tropical limpet, Cellana grata. Mar Ecol Prog Ser 124:89-103

Williams GA, Little C, Morritt D, Stirling P, Teagle L, Miles A, Pilling G, Consalvey M (1999) Foraging in the limpet Patella vulgata: the influence of rock slope on the timing of activity. J Mar Biol Assoc UK 79:881-889

Submitted: November 9, 2005; Accepted: January 28, 2006 Proofs received from author(s): August 3, 2006 